\title{
UPAYA PENGEMBANGAN SOFT SKILL SISWA SMA MELALUI PRAMUKA
}

\author{
Dwi Aprilia Wati ${ }^{1}$, Sigit Pranawa ${ }^{2}$ \& Abdul Rahman ${ }^{3}$ \\ email: dwiaprw21@gmail.com ${ }^{1}$, sigit_pranawa@staff.uns.ac.id ${ }^{2}$, \\ abdul.rahman@staff.uns.ac.id ${ }^{3}$ \\ Pendidikan Sosiologi Antropologi, Universitas Sebelas Maret
} Jalan Ir. Sutami No.36 Kentingan, Jebres, Surakarta Jawa Tengah 57126

\begin{abstract}
Abstrak: Penelitian ini mengkaji upaya pengembangan soft skill siswa SMA melalui kegiatan pramuka. Penelitian ini merupakan penelitian deskriptif kualitatif yang menggunakan teori fungsionalisme struktural dari Talcott Parsons dengan sistem AGIL, yaitu Adaptation, Goal Attainment, Integration, dan Latency sebagai dasar analisis data. Partisipan penelitian adalah 24 siswa dan 1 pembina pramuka di sebuah SMA Negeri di Kabupaten Karanganyar, Jawa Tengah. Data dikumpulkan melalui observasi, wawancara, dan dokumentasi. Hasil penelitian menunjukkan bahwa kegiatan pramuka dapat membantu mengembangkan soft skill siswa terutama kemampuan sosial dan kemampuan personal. Kemampuan sosial terdiri dari communication skill, relationship building, dan team work, sedangkan kemampuan personal terdiri dari time management, leadership skill, dan transforming character (percaya diri, tanggung jawab, mandiri, kreatif, cinta alam, dan berjiwa sosial). Kedua kemampuan soft skill dikembangkan melalui partisipasi siswa dalam kegiatan Pramuka dan keanggotaan siswa sebagai Dewan Ambalan Pramuka.
\end{abstract}

Kata-kata Kunci: pengembangan, pramuka, soft skill, struktural fungsional

\section{EFFORT TO DEVELOP HIGH SCHOOL STUDENTS' SOFT SKILLS THROUGH SCOUTING ACTIVITIES}

\begin{abstract}
This study examines efforts to develop soft skills for high school students through scouting activities. This research is a qualitative descriptive study that uses Talcott Parsons' structural functionalism theory with the AGIL system, namely Adaptation, Goal Attainment, Integration, and Latency as the basis for data analysis. Research participants were 24 students and one scout coach in a public high school in Kabupaten Karanganyar, Jawa Tengah. Data were collected through observation, interviews, and documentation. The results showed that scouting activities could help develop students' soft skills, especially social skills and personal abilities. Social skills consist of communication skills, relationship building, and team work, while personal abilities consist of time management, leadership skills, and transforming character (self-confidence, responsibility, independence, creativity, love of nature, and social spirit). Both soft skill abilities are developed through student participation in scouting activities and student membership as Scouting Council.
\end{abstract}

Keywords: development, scouting, soft skill, structural functional

\section{PENDAHULUAN}

Undang-Undang tentang Sistem Pendidikan Nasional Nomor 20 tahun 2003 Pasal 3 menyebutkan bahwa Pendidikan Nasional berfungsi untuk mengembangkan dan membentuk watak serta peradaban bangsa yang bermartabat dalam rangka mencerdaskan kehidupan bangsa. Hasil riset ini 
diharapkan menjadi bagian dari upaya mencapai tujuan pendidikan nasional, bahwasanya melalui pendidikan dapat mengembangkan soft skill siswa untuk menjadi manusia yang lebih baik

Setiap siswa berhak mengembangkan soft skill ketika belajar di SMA agar menyempurnakan kemampuan beradaptasi, mampu mengatasi persoalan dalam kehidupan dan dapat hidup secara harmoni bersama dengan orang lain. Oleh karena itu pendidikan merupakan upaya pengembangan ranah kognitif, afektif, dan psikomotorik. Ranah kognitif menumbuhkembangkan kecerdasaan intelektual akademik. Ranah afektif membentuk karakter kepribadian, dan ranah psikomotorik membentuk keterampilan (Damayanti, 2015). Sebagai kegiatan ekstrakurikuler, Pramuka menjadi bagian penting dalam pertumbuhan kepribadian siswa SMA.

Ali Ibrahim Akbar (dalam Asmani, 2013) berpendapat bahwa praktik pendidikan di Indonesia cenderung berbasis hard skill (keterampilan teknis) mengembangkan Intelligence Quotient (IQ), sedangkan kemampuan soft skill yang tertuang dalam Emotional Intelligence (EQ) dan Spiritual Intelligence (SQ) masih sangat kurang. Hasil penelitian Hardvard University mencermati sebanyak 20\% hard skill dan $80 \%$ soft skill sebagai penentu kesuksesan seseorang (Lie \& Darmasetiawan, 2017). Peranan soft skill lebih besar dari hard skill menuju kesuksesan hidup.

Soft skill dan hard skill perlu tumbuh seimbang dalam proses pendidikan sekolah, meski tidak sepenuhnya terabaikan dalam kegiatan belajar mengajar diSMA. Minimnya perhatian guru terhadap perkembangan soft skill siswa dengan melihat siswa yang kompeten adalah siswa dengan nilai ulangan tinggi, berpengaruh terhadap fokus siswa hanya untuk meningkatkan kemampuan akademis.

Selain kemampuan akademis penting bagi siswa memiliki bekal soft skill dalam menjalani kehidupan. Soft skill mencakup akal sehat dan sikap adaptif yang positif dalam berhubungan dengan orang lain dan diri sendiri (Sulianta, 2018). Penerapan soft skill tidak dapat diukur kasat mata dengan nilai angka.

Pengembangan soft skill perlu dimuat dalam kegiatan sekolah. Sesuai pernyataan Yate yang dikutip oleh Chamdani (2017) menjelaskan bahwa soft skill memungkinkan seseorang mencapai potensi diri dan mampu mengintegrasikan pengetahuan secara optimal dalam kehidupan. Pengetahuan akademis yang diajarkan di sekolah dapat dimaksimalkan apabila seimbang dengan pengetahuan soft skill.

Sebagai pelengkap kemampuan akademis, soft skill dibagi menjadi dua kategori yaitu interpersonal skill dan intrapersonal skill. Interpersonal skill merupakan kemampuan individu untuk berhubungan dengan orang lain, sedangkan intrapersonal skill adalah kemampuan individu mengatur dirinya sendiri (Wibowo, 2013). Soft skill adalah kemampuan yang tidak terbatas dan sebagai cara individu memosisikan diri di masyarakat.

Pengalaman belajar di dalam kelas kurang efektif bagi siswa mengembangkan soft skill. Siswa perlu kegiatan di luar jam sekolah untuk mengasah kemampuan non-akademis dengan mengikuti ekstrakurikuler, khususnya Pramuka. Hal ini selaras dengan hasil penelitian Meidina Siti Fatimah (dalam Sulianta, 2018) bahwa siswa perlu mengikuti ekstrakurikuler untuk mengasah kemampuan non-akademis dan mengembangkan diri dan hasil penelitian oleh Frista Kenanga yang mendukung partisipasi siswa dalam Pramuka dapat meningkatkan perilaku prososial siswa (Kenanga, 2013).

Pramuka pada satuan pendidikan memiliki fungsi pengembangan, sosial, rekreatif, dan orientasi menuju karir (Kementerian Pendidikan dan Kebudayaan, 2014). Pramuka berfungsi sebagai pengembangan sosial siswa melalui kegiatan yang menarik dan memberikan kesempatan siswa mempertajam potensi diri.

Prinsip dasar yang melandasi kegiatan Pramuka yaitu iman dan takwa kepada Tuhan Yang Maha Esa, taat kepada Kode Kehormatan Pramuka, dan peduli dengan sesama, alam, bangsa dan tanah air serta diri sendiri. Pramuka merupakan cara belajar interaktif dan progresif melalui metode learning by doing, berkelompok, kegiatan menarik di alam terbuka, pengamalan Kode Kehormatan Pramuka, tanda kecakapan sebagai penghargaan, dengan bimbingan dari orang dewasa yang terpisah antara putra dan putri (Pustaka Agung Harapan, 2017). Pramuka merupakan kegiatan menarik di alam terbuka yang dapat membiasakan diri untuk peduli dengan sesama, alam, maupun diri sendiri.

Pramuka dapat mengembangkan soft skill belajar siswa secara bebas untuk mengeksplorasi banyak hal di luar kelas. Meskipun beberapa siswa memandang kegiatan Pramuka membosankan dan melelahkan, banyak siswa yang menikmati manfaat Pramuka untuk membangun kepribadian dan pengalaman sosial dengan orang lain. Penelitian ini bertujuan untuk mengkaji upaya pengembangan soft skill siswa melalui Pramuka.

Dalam mengkaji upaya pengembangan soft skill siswa melalui pelaksanaan Pramuka digunakan teori struktural fungsional AGIL Talcott Parsons. Dua 
konsep khas dalam teori struktural fungsional Talcott Parsons yaitu sistem dan fungsi. Menurut Parsons, konsep sistem berfokus pada dua hal. Pertama, adanya ketergantungan di antara bagian dan proses keteraturan. Kedua, adanya ketergantungan dengan komponen lain dan lingkungan sekitar. Sedangkan konsep fungsi berdasarkan pada pemahaman bahwa semua sistem yang hidup merupakan kesatuan organisme sosial yang masing-masing memiliki fungsi sesuai kebutuhan (Haque et al., 2014). Berdasarkan pengertian tersebut, fungsi sistem merupakan kesesuaian antara sebuah sistem dengan kebutuhan sosial.

Lebih lanjut Parsons menjelaskan bahwa sistem agar tetap lestari perlu menjalankan empat fungsi penting yaitu Adaptation, Goal Attainment, Integration, dan Latency (Ritzer, 2012). Adapun penjelasan skema AGIL adalah sebagai berikut:

a. Adaptation (Adaptasi)

Sistem melakukan penyesuaian diri dengan

lingkungan untuk mengatasi kebutuhan mendesak dan situasional.

b. Goal Attainment (Pencapaian tujuan)

Sebuah sistem memiliki tujuan dan mampu mencapai tujuan tersebut.

c. Integration (Integrasi)

Sistem dapat mengelola hubungan antara bagian-bagian pendukung sistem agar berfungsi secara maksimal

d. Latency (Latensi)

Sistem melakukan pemeliharan, pembaruan motivasi dan pola budaya yang menopang motivasi tersebut.

\section{METODE PENELITIAN}

Penelitian ini merupakan penelitian deskriptif kualitatif sebagai proses dalam menghasilkan deskripsi kata-kata yang menggambarkan fakta, karakteristik, dan situasi terkait bidang tertentu dari pelaku yang terlibat yaitu gambaran alami dalam bentuk kata-kata terkait upaya pengembangan soft skill siswa melalui Pramuka (Suryabrata, 2016). Penelitian dilaksanakan pada bulan Februari 2020 sampai Juli 2020 bertempat di SMA Negeri Gondangrejo Jalan Solo - Purwodadi Km 11 Gondangrejo, Kabupaten Karanganyar, Jawa Tengah.

Penelitian ini menggunakan 24 partisipan siswa dan 1 partisipan Pembina Pramuka sesuai kebutuhan. Data dikumpulkan dengan kegiatan wawancara, observasi, dan dokumentasi yang dianalisis menggunakan model analisis data Miles dan Huberman yaitu melalui tahap pengumpulan data, reduksi data, penyajian data, hingga menarik kesimpulan. Uji kevalidan data menggunakan triangulasi sumber dengan membandingkan hasil wawancara informan untuk meningkatkan pemahaman data dan menghindari satu sudut pandang.

\section{HASIL DAN PEMBAHASAN}

\section{Hasil}

Pramuka merupakan kegiatan di luar jam pelajaran sekolah sebagai sarana implementasi pengetahuan secara umum dan untuk mengembangkan potensi diri siswa pada khususnya. Tujuan pelaksanaan kegiatan Pramuka membentuk manusia budi pekerti dan beriman takwa, memiliki kecerdasan dan keterampilan, memiliki kesehatan jasmani rohani, dan menjadi manusia berjiwa Pancasila (Esensi, 2012).

Gerakan Pramuka di SMA objek penelitian ini, khususnya pada ambalan Bima Sakti Sekar Langit berusaha mencapai tujuan sekolah yaitu meningkatkan kualitas sumber daya manusia dan membentuk insan cendekia yang bermartabat melalui pelaksanaan Pramuka. Bentuk kegiatan Pramuka meliputi kegiatan berkemah, penjelajahan, pelatihan/ pendidikan, lomba kepramukaan, dan kegiatan sosial. Kegiatan berkemah meliputi kemah raya, kemah Dianpinsa (Gladian Pimpinan Sangga), Persami (Perkemahan Sabtu Minggu), dan kemah bakti. Kegiatan penjelajahan meliputi lintas alam dan lintas purba. Kegiatan pelatihan atau pendidikan meliputi pertemuan rutin, PTA (Penerimaan Tamu Ambalan), Bantara, dan Napak Tilas. Kegiatan sosial meliputi bakti sosial dan Car Free Day. Kegiatan Pramuka di alam terbuka merupakan model pembelajaran kemandirian dalam pendidikan yang sangat efektif untuk mengimplementasikan nilai hidup (Muchtar \& Trisnamansyah, 2011). Kegiatan Pramuka dapat melatih siswa menuju kedewasaan.

Seluruh kegiatan Pramuka dibimbing dan difasilitasi oleh Pembina Pramuka dengan bantuan Dewan Ambalan Pramuka. Pembina Pramuka memotivasi, mengapresiasi, dan memberi bimbingan jasmani maupun rohani selama proses pendidikan Pramuka. Sedangkan Dewan Ambalan melaksanakan dan menjalankan kegiatan Pramuka sesuai bimbingan Pembina Pramuka.

Pelaksanaan Pramuka SMA Negeri Gondangrejo dijalankan dengan model blok yaitu bersifat wajib satu tahun sekali oleh seluruh peserta didik dan memiliki penilaian umum. Peserta didik wajib Pramuka 
adalah siswa kelas $\mathrm{X}$ sedangkan Dewan Ambalan merupakan anggota Pramuka kelas XI yang telah disahkan sebagai Dewan dari Ambalan Pramuka untuk menjalankan Pramuka pada satuan pendidikan SMA dan mendampingi adik-adik Pramuka kelas $X$. Hal ini sesuai dengan prinsip dasar pelaksanaan Pramuka Penegak yaitu dari, oleh, dan untuk Pramuka Penegak itu sendiri. Dewan Ambalan dipimpin oleh seorang ketua disebut Pradana dan memiliki seorang wakil yang disebut Pradani, dengan susunan pengurus sebagai berikut:

a. Pradana sebagai pemimpin yang mengatur dan memegang wewenang tugas yang akan dijalankan oleh Dewan Ambalan.

b. Pradani sebagai wakil pemimpin yang membantu menjalankan tugas Pradana.

c. Pemangku Adat sebagai penasehat ataupun penengah dalam menyelesaikan masalah dalam Pramuka.

d. Kerani sebagai sekretaris dewan yang mengurus pembukuan, laporan, dan segala hal keadministrasian.

e. Juru uang sebagai bendahara dewan yang mengatur keuangan.

f. Tekpram atau Teknik Kepramukaan bertanggung jawab menentukan materi Pramuka yang akan diajarkan.

g. Perlengkapan bertugas menyediakan sarana dan prasarana kegiatan Pramuka.

h. Giat operasional bertanggung jawab dalam kedisiplinan dan ketaatan peraturan anggota Pramuka.

Sebagai pengemban dan pelaksana kegiatan Pramuka, siswa memiliki beragam pengalaman dan kesempatan untuk mengembangkan potensi diri melalui keanggotaan sebagai Dewan Ambalan. Sehingga partisipasi siswa dalam kegiatan Pramuka dan keanggotaan siswa sebagai Dewan Ambalan Pramuka melatih siswa mengembangkan soft skill terutama kemampuan sosial dan kemampuan personal. Siswa perlu mengembangkan kemampuan sosial dan kemampuan personal sebagai bekal menjalani kehidupan dan menghadapi masa depan.

Kemampuan sosial merupakan kemampuan siswa untuk bergaul, berhubungan, dan bekerja sama secara individu maupun kelompok di dalam masyarakat (Amtorunajah, 2015). Kemampuan sosial menjadi kunci untuk bersosialisasi dan berinteraksi. Kemampuan sosial perlu dikembangkan agar tidak menjadi penghambat di kehidupan bersosial. Pramuka mengembangkan kemampuan sosial siswa terutama communication skill, relationship building, dan team work.

Dasar manusia sebagai makhluk sosial menuntut manusia berhubungan dengan orang lain agar dapat bertahan hidup. Melalui komunikasi siswa dapat berinteraksi, membaur, menjalin hubungan, berbagi pikiran, pendapat, dan perasaan dengan siapapun, kapanpun, dan dimanapun (Al'Aththar, 2012). Berdasarkan pernyataan tersebut komunikasi menjadi modal siswa dalam membangun hubungan dan menciptakan kerja sama tim.

Selain mengembangkan kemampuan sosial, siswa mengembangkan kemampuan personal melalui Pramuka. Kemampuan personal merupakan kemampuan mengatur dan mengelola diri sendiri secara optimal (Iriani, 2017). Pengembangan kemampuan personal akan membentuk sikap, sifat, dan karakter siswa yang baik. Kemampuan personal perlu dilatih agar siswa secara optimal menghasilkan kinerja terbaik dalam dirinya. Pramuka mengembangkan kemampuan personal siswa terutama time management, leadership skill, dan transforming character yang terdiri atas kepercayaam diri, kedisiplinan, tanggung jawab, mandiri, kreatif, cinta alam, dan jiwa sosial).

\section{Pembahasan}

Pelaksanaan Pramuka SMA Negeri Gondangrejo dalam mengembangkan soft skill siswa dapat berkembang dengan menjalankan empat fungsi imperatif seperti yang dapat dilihat dalam gambar 1 .

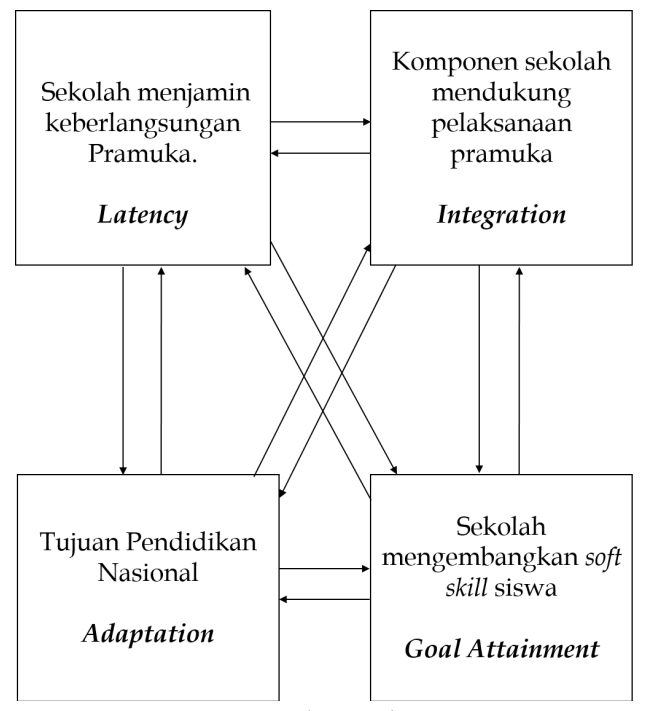

Gambar 1. Analisis skema AGIL

Berdasarkan gambar 1, dapat dijelaskan sebagai berikut:

\section{Adaptation (Adaptasi)}

Fungsi adaptasi yaitu sebuah sistem mampu beradaptasi, mengatasi situasi, dan menyesuaikan diri untuk memenuhi kebutuhan situasional. Sesuai Undang-Undang Sistem Pendidikan Nasional Nomor 
20 Tahun 2003 kondisi pendidikan di Indonesia diharapkan mampu mengembangkan potensi siswa agar menjadi manusia yang beriman takwa kepada Tuhan Yang Maha Esa, berakhlak terpuji, cakap, dan menjadi warga Negara yang demokratis bertanggung jawab dapat di ciptakan melalui pendidikan yang dilaksanakan di sekolah.

Pendidikan sebagai upaya mengembangkan kemampuan kognitif, afektif, dan psikomotorik siswa (Damayanti, 2015). Pendidikan tidak hanya memberikan kesempatan bagi siswa untuk mengembangkan kemampuan akademis (hard skill) namun juga kemampuan non-akademis (soft skill). Sekolah berupaya melaksanakan proses pendidikan yang meliputi pengembangan kedua ranah kemampuan tersebut. Akan tetapi untuk menyeimbangkan kemampuan hard skill maupun soft skill tidak didapatkan siswa hanya dengan mengikuti kegiatan belajar di sekolah. Siswa perlu mengikuti kegiatan di luar jam sekolah agar dapat menyeimbangkan kemampuan hard skill yang diperoleh dengan memiliki kemampuan soft skill untuk menjadi anggota masyarakat yang baik.

Sistem sekolah melakukan penyesuaian diri untuk mendukung tujuan Pendidikan Nasional tersebut dengan menyadari pentingnya pengembangan kemampuan soft skill siswa SMA menjadi manusia yang baik dalam menjalani kehidupan masyarakat. Melalui Pramuka siswa mengembangkan kemampuan soft skill dengan mengikuti kegiatan Pramuka dan menjadi anggota Dewan Ambalan Pramuka. Adaptasi juga dilakukan oleh Pramuka sebagai kegiatan ekstrakurikuler di luar jam sekolah yang memfasilitasi siswa dengan berbagai kegiatan Pramuka dan keorganisasian siswa yaitu Dewan Ambalan untuk mengatasi situasi dalam mewujudkan sistem Pendidikan Nasional bahwasanya melalui pendidikan akan membentuk watak peradaban manusia dalam rangka mencerdaskan kehidupan bangsa-bangsa.

\section{Goal Attainment (Pencapaian Tujuan)}

Pencapaian tujuan merupakan fungsi yang harus dijalankan sebuah sistem untuk dapat mendefinisikan tujuan dan mampu mencapai tujuan tersebut. Tujuan bersama yang ingin dicapai dalam sistem sekolah yaitu mengembangkan kemampuan soft skill sebagai salah satu upaya menjadikan siswa sebagai manusia yang cakap, mandiri, dan menjadi warga negara yang demokratis serta bertanggung jawab sesuai harapan tujuan Pendidikan Nasional di Indonesia.

Dalam mencapai tujuan pengembangan soft skill, sekolah memfasilitasi dan menjamin keberlangsungan pelaksanaan Pramuka dengan memberikan dukungan sarana prasarana, Pembina Pramuka yang akan membimbing kegiatan Pramuka sehingga dapat mengoptimalkan manfaat pelaksanaan kegiatan tersebut, serta siswa yang mau mengarahkan diri untuk mengikuti Pramuka sebagai wahana mengembangkan kemampuan sosial dan personal. Pramuka memiliki tujuan secara umum untuk membentuk manusia budi pekerti, beriman dan takwa, memiliki kecerdasan dan keterampilan, sehat jasmani rohani, dan menjadi manusia berjiwa Pancasila yang peduli dengan sesama manusia dan alam. Pramuka berusaha turut meningkatkan kualitas sumber daya manusia dan membentuk insan cendekia yang bermartabat, menumbuhkan kepercayaan diri, dan semangat pengabdian kepada masyarakat. Sehingga pramuka dapat mendukung dan memfasilitasi siswa dalam upaya mengembangkan kemampuan soft skill.

Kemampuan soft skill siswa yang berkembang meliputi kemampuan sosial dan kemampuan personal. Kemampuan sosial merupakan kemampuan siswa untuk berhubungan, bergaul, dan bekerja sama dengan orang lain. Tujuan siswa mengembangkan kemampuan sosial agar siswa dapat membaur dan menjalin hubungan dengan orang lain sehingga dalam proses menjalani kehidupan sosial siswa tidak terhambat oleh kemampuan sosialnya. Kemampuan sosial yang dikembangkan siswa SMA melalui Pramuka meliputi communication skill, relationship building, dan team work. Kemampuan berkomunikasi digunakan siswa agar siswa dapat berinteraksi dengan orang lain sehingga melalui interaksi tersebut akan menjalin suatu hubungan yang solid dan mampu menciptakan kerja sama tim yang baik

Sedangkan, kemampuan personal merupakan kemampuan yang dimiliki oleh siswa untuk mengatur dirinya sendiri. Tujuan siswa mengembangkan kemampuan personal agar siswa dapat memahami, menganalisis, dan mengelola diri sendiri untuk dapat menghasilkan kinerja terbaik dalam dirinya. Pengembangan kemampuan personal siswa melalui Pramuka meliputi time management, leadership skill, dan transforming character. Kemampuan dalam mengelola diri dan memiliki karakter yang baik dapat membantu siswa mendapat hasil optimal dari seluruh pekerjaan yang dilakukan.

\section{Integration (Integrasi)}

Menjaga keberlangsungan agar sistem tetap hidup dan lestari, sistem harus mampu mengatur hubungan bagian-bagian komponen pendukungnya. 
Sekolah mengintegrasikan tujuan pengembangan soft skill siswa ke dalam pelaksanaan Pramuka dengan cara melatih dan mengembangkan kemampuan soft skill terutama kemampuan sosial dan personal selama siswa mengikuti kegiatan Pramuka dan melaksanakan tugas sebagai Dewan Ambalan Pramuka.

Kemampuan sosial yang dilatih dan dikembangkan meliputi communication skill, relationship building, dan team work saat kegiatan berkemah, penjelajahan, dan menjadi pengurus Dewan Ambalan. Siswa mampu mengembangkan kemampuan sosial saat kegiatan berkemah dan penjelajahan untuk memecahkan teka-teki di setiap pos penjagaan, menyelesaikan game, mendirikan tenda, menyelesaikan misi mencari jejak, dan membuat pionering siswa harus berinteraksi dengan orang lain, saling bertukar pendapat, berdiskusi, dan memberi dukungan. Interaksi yang dilakukan siswa dengan orang lain melatih siswa untuk dapat berbaur dan bergaul dengan teman dan lingkungan. Adanaya interaksi akhirnya membangun suatu hubungan dan menghasilkan kerja sama tim yang baik.

Siswa dewan juga dapat melatih kemampuan sosial team work saat melaksanakan tugas sebagai Dewan Ambalan. Sebagai pelaksana kegiatan Pramuka Penegak di SMA Dewan Ambalan memiliki tugas masing-masing sesuai bagian. Dengan adanya pembagian tugas tersebut siswa melatih kemampuan kerja tim mereka dan membangun hubungan dengan menempatkan rasa saling percaya antar anggota dewan dalam melaksanakan kegiatan Pramuka dengan kompak.

Selanjutnya kemampuan personal yang dilatih dan dikembangkan siswa melalui Pramuka SMA meliputi time management, leadership skill, dan transforming character. Cara siswa mengelola waktu untuk menyelesaikan misi di setiap titik pos kegiatan penjelajahan melatih siswa untuk disiplin dalam menggunakan waktu, menentukan strategi, dan mencapai tujuan. Adanya sanksi yang dikenakan jika tidak dapat menyelesaikan pekerjaan dengan tepat waktu, melatih siswa agar bijaksana mengelola waktu dan selalu mempertimbangkan timing.

Pengembangan jiwa kepemimpinan dapat dilatih dalam kegiatan Pramuka yaitu saat menjadi ketua regu, menjadi pemimpin upacara atau apel, menjadi pemimpin sangga, dan menjadi pengurus ambalan. Karakter tanggung jawab, disiplin, percaya diri, dan pantang menyerah juga berkembang dalam kegiatan Pramuka yang diikuti siswa. Belajar menjadi seorang pemimpin sekaligus membuat siswa belajar untuk tanggung jawab. Tanggung jawab dalam
Pramuka dilatih dengan membiasakan siswa berani mengakui kesalahan, disiplin menaati peraturan, tertib dalam berpakaian, dan menjalankan amanah yang telah diberikan. Karakter percaya diri juga dilatih dan dikembangkan siswa melalui kegiatan Pramuka dan keanggotaan Dewan Ambalan yang membiasakan siswa berani untuk berbicara di depan umum.

Proses integrasi yang dilakukan dengan melatih dan membiasakan indikator kemampuan soft skill ke dalam kegiatan Pramuka dan keanggotaan Dewan Ambalan Pramuka di sekolah dapat mengembangkan kemampuan sosial dan kemampuan personal siswa guna mencapai tujuan bersama yaitu pengembangan soft skill melalui Pramuka SMA.

\section{Latency (Latensi)}

Fungsi latensi merupakan pemeliharaan pola yang sudah berjalan oleh sistem untuk meningkatkan dan mempertahankan motivasi. Sekolah mempertahankan dan melakukan pemeliharaan terhadap pelaksanaan Pramuka yang meliputi kegiatan-kegiatan Pramuka dan keaktifan organisasi Dewan Ambalan Pramuka. Adanya program kerja tahunan yang memuat kegiatan rutin Pramuka merupakan salah satu bentuk pemeliharaan yang dilakukan agar Pramuka tetap memfasilitasi siswa dalam upaya mengembangkan kemampuan soft skill. Pemeliharaan juga dilakukan dengan memberikan nilai ekstrakurikuler pada laporan nilai siswa dan kesempatan kepada siswa untuk menjadi anggota Dewan Ambalan dengan adanya regenerasi anggota dewan setiap satu tahun sekali. Hal ini dilakukan untuk meningkatkan dan memperbarui motivasi siswa SMA mengikuti Pramuka dalam mencapai tujuan pengembangan soft skill.

\section{PENUTUP}

\section{Kesimpulan}

Berdasarkan hasil dan pembahasan penelitian maka dapat diambil kesimpulan pengembangan soft skill siswa SMA melalui partisipasi siswa dalam kegiatan Pramuka dan keanggotaan siswa sebagai Dewan Ambalan Pramuka. Pengembangan soft skill Pramuka meliputi pengembangan kemampuan sosial dan kemampuan personal.

Kemampuan sosial siswa untuk bergaul, berhubungan dan bekerja sama secara individu maupun kelompok di dalam masyarakat terdiri atas communication skill, relationship building dan team work.

Kemampuan personal siswa sebagai kemampuan untuk mengelola dan mengatur diri sendiri terdiri atas time management, leadership skill, 
dan transfoming character terutama kepercayaan diri, tanggung jawab, disiplin, mandiri, kreatif, cinta alam, dan jiwa sosial.

Pelaksanaan Pramuka SMA Negeri Gondangrejo sebagai upaya pengembangan soft skill siswa diadaptasikan (Adaptation) sesuai tujuan Pendidikan Nasional, dimaksudkan untuk mencapai tujuan (Goal Attainment) dalam pengembangan soft skill siswa terutama kemampuan sosial dan kemampuan personal, dan diintegrasikan ke dalam kegiatan Pramuka dan Dewan Ambalan Pramuka (Integration), yang kemudian dilakukan pemeliharaan (Latency) untuk meningkatkan motivasi siswa mengikuti Pramuka.

\section{Saran}

Perbaikan terkait pengembangan soft skill siswa melalui Pramuka diberikan dalam bentuk saran kepada siswa, Dewan Ambalan, Pembina Pramuka, Kepala Sekolah dan guru.

Siswa perlu meningkatkan antusiasme dengan disiplin mengikuti Pramuka sebagai penunjang siswa mengembangkan kemampuan sosial dan kemampuan personal.

Dewan Ambalan perlu menjaga kekompakan anggota dewan agar tetap aktif dalam melaksanakan Pramuka. Pembina Pramuka perlu menjaga dan mengayomi anggota Pramuka untuk mengoptimalkan manfaat pelaksanaan Pramuka dengan mendisiplinkan kehadiran siswa.

Kepala Sekolah dan guru mendukung siswa mengembangkan kemampuan hard skill maupun soft skill dan menjamin keberlangsungan Pramuka sebagai salah satu wahana pengembangan soft skill siswa.

\section{DAFTAR PUSTAKA}

Al' Aththar, M. A. (2012). Pentingnya Komunikasi dalam Kehidupan Manusia (I). Jakarta: Zaman.

Amtorunajah. (2015). Peningkatan Keterampilan Sosial Siswa Dalam Pembelajaran IPS melalui Outdoor Activity DiSMP Negeri 1 Kaligondang Kabupaten Purbalingga. Harmoni Sosial: Jurnal Pendidikan IPS, 2(1), 1-11, DOI: 10.21831/hsjpi. v2i1.4598

Asmani, J. M. (2013). Buku Panduan Internalisasi Pendidikan Karakter di Sekolah VI. Jogjakarta: DIVA Press.

Chamdani, M. (2017). Penerapan Mind Map Pada Mata Kuliah Perkembangan Belajar Peserta Didik Untuk Pengembangan Soft Skill Mahasiswa PGSD. Jurnal Dwija Cendekia, 1 (1), 61-72, DOI: 10.20961/jdc.v1i1.14408
Damayanti, D. (2015). Panduan Implementasi Pendidikan Karakter di Sekolah (1st ed.; Iyan AR, ed.). Yogyakarta: Araska.

Esensi, T. (2012). Mengenal Gerakan Pramuka. Jakarta: Esensi.

Haque, A., Wang, Z., Chandra, S., Dong, B., Khan, L., \& Hamlen, K. W. (2014). Alasan Talcott Parsons Tentang Pentingnya Pendidikan Kultur. Ijtimaiyya, 7(1), 919-928, DOI: 10.1145/3132847.3132886.

Iriani, T. (2017). Studi Analisis terhadap Kemampuan Softskill Mahasiswa Fakultas Teknik UNJ. Jurnal Pensil Pendidikan Teknik Sipil, 6(1), 1-13, DOI: 10.21009/jpensil.v6i1.7472

Kementerian Pendidikan dan Kebudayaan. (2014). Kepramukaan: Bahan Ajar Implementasi Kurikulum 2013 untuk Kepala Sekolah. Jakarta: Kemdikbud

Kenanga, F. (2013). Pengaruh Partisipasi Siswa Dalam Ekstrakurikuler Effect of the Student Participation in Scout Extracurriculum on the Prosocial Behavior of Primary. VISI: Jurnal Ilmiah PTK PNF, 9(2), 132-139, DOI: 10.21009/ JIV.0902.7

Lie, NLC \& Darmasetiawan, N. K. (2017). Pengaruh Soft Skill Terhadap Kesiapan Kerja Menghadapi Masyarakat Ekonomi Asean Pada Mahasiswa S1 Fakultas Bisnis Dan Ekonomika. Calyptra: Jurnal Ilmiah Mahasiswa universitas Surabaya, 6(2), 1496-1514. Diakses melalui https:// journal.ubaya.ac.id/index.php/jimus/article/ view/1074/862 .

Muchtar, U. M., \& Trisnamansyah, S. (2011). Implementasi Model Pembelajaran Kemandirian Generasi Muda Mandiri Pada Kegiatan Alam Terbuka. VISI: Jurnal Ilmiah PTK PNF, 6(2), 144153, DOI: 10.21009/JIV.0602.5

Pustaka Agung Harapan, T. (2017). Panduan Lengkap Gerakan Pramuka (Sokeh, ed.). Surabaya: Pustaka Agung Harapan.

Ritzer, G. (2012). Teori Sosiologi Dari Sosiologi Klasik Sampai Perkembangan Terakhir Postmodern, W. A. Djohar, ed. Yogyakarta: Pustaka Pelajar.

Sulianta, F. (2018). Panduan Lengkap Pengembangan Softskill- Interpersonal dan Intrapersonal Skill (Mayasari, ed.). Yogyakarta: ANDI.

Suryabrata, S. (2016). Metodologi Penelitian (2nd ed.). Jakarta: Rajawali Pers.

Wibowo, A. (2013). Pendidikan Karakter di Perguruan Tinggi. Malang: Pustaka Pelajar 
Upaya Pengembangan Soft...

124 PERSPEKTIF Ilmu Pendidikan - Vol. 34 No. 2 Oktober 2020 